\title{
M imesis e rememoração da natureza no sujeito em Theodor W. Adorno: para pensar a educação do corpo na escola ${ }^{1}$
}

\author{
Jaison José Bassani* e AlexandreFernandez Vaz ${ }^{* *}$
}

Resumo: A partir das contribuições daTeoria C rítica da Sociedade, deT heodor W. Adorno, 0 presentetrabal ho dedica-sea uma reflexão epistemológica e pedagógica sobreo tema do corpo esuas expressões, em especial no que se referea dois de seus motivos originais: a questão da mi mesis e a da rememoração da natureza no sujeito. Como resultado, destaca-se a posição dialética que o corpo ocupa no processo de esquecimento e denegação da natureza no sujeito, na medida em que, se a ideia de natureza eda memória do sujeito em relação a el a éexpressão de uma subjetividade incerta e petrificada, por outro lado, no entanto, a partir da valorização do comportamento mimético no âmbito das práticas corporais, constitui-sea possi bilidadede resistência aosimperativos daracionalidadeinstrumental.

Palavras-chave: educação do corpo; rememoração da natureza; mimesis.

Mimesis and remembrance of nature in the subject by Theodor W. Adorno: thinking body education at school

Abstract: Based on the contributions from the C ritical Theory of Society of Theodor W. Adorno, this paper makes an epistemological and pedagogical reflection on body and its expressions, specially on two original forces: mimesisand remembrance of naturein thesubject. The body finds a dialectical place in the process of forgetting and refusing nature in the

* Professor do D epartamento de Educação Física e dos Programas de Pós-G raduação em Educação e Educação Física da U niversidade Federal de Santa Catarina (UFSC) e membro do N úcleo de Estudos e Pesquisa Educação e Sociedade Contemporânea (UFSC-U FPR/CN Pq), Brasil. jaisonbassani@uol.com.br

** Professor dos Programas de Pós-G raduação em Educação e Interdisciplinar em Ciências H umanas da Universidade Federal de Santa Catarina (UFSC) e Coordenador do N úcleo de Estudos e Pesquisa Educação e Sociedade Contemporânea (UFSC -U FPR/CN Pq), Brasil. Pesquisador CN Pq. alexvaz@uol.com.br

1. O trabalho apresenta resultados parciais dos projetos Corpo e rememoração da natureza no sujeito: uma investigação na dimensão pedagógica da filosofia de Theodor W. Adorno, financiado pelo CN Pq (Processo n. 400681/2009-9, Edital MCT/CN Pq 02/2009), e Teoria Crítica, Racionalidades e Educação II, financiado pelo C N Pq (Processos n. 572119/2008-9, 502892/2008-0, 308912/ 2007-1, 503353/2007-8). 
subject. If nature and the subject's memory are an expression of an uncertain and stoned subjectivity, mimetic behavior in corporal practicesishowever a possibility or resistanceagainst instrumental rationality.

Key words: body education; nature remembrance; mimesis.

\section{Prólogo}

0 presente trabal ho dedica-se a uma reflexão sobre o tema do corpo e algumas de suas expressões na obra de Theodor W. Adorno, em especial em dois de seus motivos centrais, os temas da mimesis e da rememoração da natureza no sujeito. Pretende, com isso, levantar algumas de suas implicações para a compreensão da educação do corpo na sociedade contemporânea, em especial no registro da escolarização.

$\mathrm{N}$ a forma de um conhecimento não conceitual e expressivo, passando pelo caráter de instrumento de dominação política e encontrando seu desiderato na dialética entre espontaneidade e dominação do corpo e suas virtualidades, 0 conceito de mimesis permite que se discuta a contribuição de Adorno no que diz respeito ao tema das práticas corporais e do esporte, em particular, como expressão de uma dialética do esclarecimento. Por sua vez, a rememoração da natureza no sujeito encontra, em seu potencial de resistência aos processos de reificação, um lugar na recondução do caráter autorreflexivo, não no sentido de restauração de uma "condição perdida", mas de reconciliação concreta entre sujeito e natureza, universal e particular.

0 texto, em sua primeira parte, dedica-se ao conceito de mimesis, seus destinos inscritos, como dito, em uma dialética do esclarecimento, considerando, com H orkheimer (2000), que o corpo é, por excelência, o órgão de expressão mimética. Logo após, procurando dar consequência ao debate anteriormente desenvolvido, toma o tema do esporte e das práticas corporais em suas possibilidades de expressão mimética e de recordação da natureza a compor o sujeito autorreflexivo. N ela, a título de considerações finais, alguns elementos são sugeridos e retomados, numa tentativa de síntese e na expectativa de que algumas problemáticas em relação à educação do corpo possam alcançar um novo plano de reflexão.

\section{Corpo, mimesis e rememoração da natureza no sujeito}

Se podemos considerar a proposição de Adorno, segundo a qual a cultura está fundada na separação primordial entre sujeito e objeto, entre corpo e espírito (Geist), como expressão do processo imemorial de domínio da natureza e forja do sujeito - processo nada indolor e coagulado de consequências -, então 
a reconciliação (Versöhnung) entre sujeito e objeto, entre humano e natureza, está muito longe de ser postulada como uma meta facilmente alcançável.

Apesar de doloroso, esse processo de separação entre sujeito e objeto significa, antes de tudo, para Adorno, um momento fundamental e progressista no percurso de formação do sujeito e na tentativa de romper com o ciclo inescapável e cego do mundo mitológico, o que "[...] está aí desde sempre" (Adorno, 2003, p. 589; 1991a, p. 104) ${ }^{2}$ e diz respeito ao mundo natural ainda não transformado pelo trabalho, ainda não mediado pela história, não conhecido; em uma palavra, não humanizado, e que representa uma ameaça ao homem, um fora de controle. Por um lado, pode-se dizer que Adorno, assim como seu parceiro intelectual $\mathrm{M}$ ax $\mathrm{H}$ orkheimer, identifica, potencialmente, "a loucura coletiva que hoje vagueia pelo mundo" (H orkheimer, 2000, p. 176), na separação imemorial entre sujeito e objeto, ou seja, quando, pela primeira vez, o humano objetificou a natureza para poder dominá-la; por outro, é igualmente verdade que o filósofo frankfurtiano sempre foi hostil a toda e qualquer espécie de nostalgia - teórica ou social - em relação a uma fase "pré-histórica", supostamente harmônica. Para ele, essa separação que se encontra materializada na história da civilização ocidental - daí seu caráter "real", do qual nos fala no texto "Sobre sujeito e objeto" (Adorno, 2003, p. 8630-8631; 1995b, p. 182-183) -, antes de ser aprofundada ou suprimida, não deveria ser esquecida, uma vez que isso significaria recalcar o sofrimento que Ihe dá origem e que dela se origina; sua possível superação, por outro lado, não depende da vontade do observador, mas da transformação das condições históricas que a produziram: "[...] a imagem de um estado originário, temporal ou extra-temporal, de feliz identificação de sujeito e objeto, é romântico; por longo tempo, projeção da nostalgia, hoje reduzida à mentira." (Adorno, 2003 p. 8630-8631; 1995b, p. 183).

Essa procura pela reconciliação entre sujeito e objeto, no estado de coisas no qual vivemos no "mundo administrado" (Verwaltete Welt), não seria possível e, talvez, nem desejável para Adorno, que vê como funesta e ideológica a projeção, como algo que já estivesse realizado, daquilo que na realidade se encontra irreconciliado. Como afirma em Dialética negativa, "enquanto 0 mundo permanecer como é, todas as imagens de reconciliação, de paz e tranquilidade assemelham-se à imagem da morte." (Adorno, 2003, p. 3449; 2009, p. 316; Alves Jr., 2001, p. 118). Seguindo os passos de Walter Benja-

2. Todas as citações de Adorno realizadas neste trabalho referem-se à edição digital (Digitale Bibliothek Band 97 - Biblioteca D igital, v. 97), de 2003, das obras reunidas (Gesammelte Schriften) editadas pela Suhrkamp Verlag (1986). 0 número da página indicado corresponde à paginação da edição digital. Após o ponto e vírgula, acrescenta-se a referência da tradução correspondente em português e espanhol. 
min $(1985)^{3}$, Adorno parece permitir-se apenas especular sobre um possível "estado de paz" entre sujeito e objeto (Adorno, 2003, p. 8631-8632; 1995b, p. 184), enfatizando o poder da "memória" (Gedächtnis), "a lembrança referencial de um objeto sempre pré-vivo ao sujeito que relembra." (Jay, 1988, p. 64). No entanto, não se trata de um "relembrar" algo desmembrado, recuperando uma suposta plenitude pretérita. A ideia da "recordação" do objeto no sujeito, para Adorno (2003, p. 3116-3138; 2009, p. 157-162), significa, como ruptura com a lógica da filosofia da identidade, a recondução da "diferença" (o "não-idêntico") ao seu lugar adequado, o que significa afirmar, nos termos de uma "dialética negativa", o "primado do objeto" (Vorrang des 0 bjekts). No entanto, isso não implica o estabelecimento de uma nova hierarquia entre forças objetivas e subjetivas, na forma de uma inversão de polaridade: elevar o objeto ao trono ocupado pelo sujeito significaria convertê-lo em ídolo, diz Adorno (2003, p. 3112-3113; 2009, p. 155). Como assevera categoricamente 0 autor em "Sobre sujeito e objeto", a prioridade advogada ao objeto não emerge em detrimento do sujeito: "se ele [0 sujeito] fosse liquidado em vez de superado numa forma mais elevada, isso operaria não somente a regressão da consciência, mas sim a recaída em uma real barbárie." (Adorno, 2003, p. 8631; 1995b, p. 183-184). 0 que deve ser buscado é, pelo contrário, a eliminação dessa hierarquia, ou seja, "um estado de diferenciação sem dominação, na qual o diferente é compartido" (Adorno, 2003 , p. 8631-8632; 1995b, p. 184), de forma que se pense uma unidade- entre as duas esferas - que as mantenha, ao mesmo tempo, diversidades: "A contemplação não-violenta, de onde vem toda a felicidade da verdade, está vinculada à condição de que o contemplador [sujeito] não incorpore o objeto: proximidade à distância." (Adorno, 2003, p. 1808; 1993, p. 77, grifo nosso).

Como indicam Horkheimer e Adorno (2003; 1985) em D ialética do esclarecimento, obra-chave do pensamento frankfurtiano, a fratura sujeito-objeto não se dá em relação apenas à "natureza externa", mas também à do próprio corpo, "interna". Ao alhear-se daquela para poder dominá-la e operacionalizála, o humano acaba tornando-se também objeto, na medida em que é parte (da) natureza. Aquilo que temos de natureza, mesmo que inevitavelmente mediado pela cultura, pela linguagem - nosso corpo e suas expressões - também é, na forma das paixões e das indeterminações, visto como algo ameaçador e desconhecido e, portanto, precisa ser dominado. Foi a racionalidade ocidental que

3. Para uma maior compreensão das relações tanto de proximidade quanto de distanciamento entre Adorno e Benjamin, consultar, entre outros, N obre (1998, p. 59-102), Agamben (2005, p. 129-150), Buck-Morss (1981), Chiarello (2007) e Gagnebin (2007). 
instruiu homens e mulheres a dominarem seus impulsos a ponto de poderem cada vez mais contribuir, por meio do seu trabal ho - como dito acima, o processo contínuo de tranfformação deliberadamente humana da natureza - , para construir a civilização e os benefícios, incluindo a segurança e as riquezas, que esta mesma racionalidade é capaz de gerar (Freitas, 2003). Ao contribuir para a formação da cultura, cada um pôde, simultaneamente, nesse processo de domínio de sua dimensão corporal, de seus sentimentos, de seus desejos, formar-se sujeito consciente de sua própria individualidade. $D$ ito de outra forma, a relação com o corpo representa um momento fundamental da cisão entre sujeito e objeto, que se afigura, neste caso, por meio da relação entre uma dimensão não corporal (espírito, razão, mente) que exerce senhorio sobre outra, o corpo, o próprio e o de outros, visto como objeto a ser conhecido e controlado (Vaz, 1999).

No que se refere especificamente à relação do humano com a natureza, tanto externa quanto interna, emerge do quadro descrito acima o conceito de "rememoração" (Eingedenken), no sentido específico atribuído pelo filósofo frankfurtiano, de recuperação do momento de não identidade no sujeito, ou seja, de sua dimensão de natureza. Adorno sabe que, conforme postula a psicanálise, a memória da natureza, como elemento reprimido pelo percurso de constituição da civilização e do próprio sujeito, pode aflorar de modo perverso, com força destrutiva e repressiva. I sso é o que ocorre em regimes de força, como os populistas e, em especial, os totalitários. Exemplo marcante teria sido o nazismo, que, ao promover uma falsa reconciliação entre espírito e natureza, entre indivíduo e sociedade, funcionalizou a "revolta da natureza" (H orkheimer, 2000, p. 97), colocando-a novamente, por meio da suspensão do interdito do mecanismo pulsional, a serviço da repressão. É o que acontece também no âmbito da indústria cultural, que, ao prometer indefinidamente, por meio de suas mercadorias, algo que não pode ser cumprido, gera não a sublimação, mas a repressão da pulsão. É em reação a esse estado de coisas que se contrapõe a noção adorniana de "rememoração da natureza no sujeito" (Eingedenken der Natur im Subjekt). Conforme destaca Alves Jr. (2001, p. 125), se 0 antissemitismo e a indústria cultural realizam, de forma maldosa e perversa, uma reconciliação entre humano e natureza, caberia, no espírito da dialética negativa adorniana, valorizar a ideia de que é somente na separação refletida entre ambos os polos - quando identidade e não identidade possam encontrar um lugar não hierárquico - que se encontra a possibilidade de reconciliação. "O espírito que recorda seu momento de naturalidade poderia, com efeito, desembaraçar-se do destino, imposto pelo esclarecimento, que o obriga a voltar-se contra ela como violência." (Alves J r., 2001, p. 125). Por meio do exercício do conceito - cuja origem está naquilo que não é conceitual -, e não 
contra ele, é que pode a natureza ser alcançada, não em sentido literal, mas como momento esclarecedor da razão:

0 esclarecimento émais que o esclarecimento: natureza quese torna perceptível de sua alienação. $\mathrm{N}$ o autoconhecimento do espírito como natureza em desunião consigo mesma, a natureza se chama a si mesma como antigamente [...]. G raças a essa rememoração [Eingedenken] da natureza no sujeito, queencerraa verdade ignorada detoda a cultura, o esclarecimento se opõeà dominação em geral. (H orkheimer; Adorno, 2003, p. 1167; 1985, p. 50, tradução ligeiramentemodificada, grifo nosso).

É na recordação do que há de natureza no humano que podemos inscrever a dimensão do conceito de mimesis como atitude (re)conciliatória, especialmente no complexo da relação com o corpo e suas expressões, do sujeito com 0 objeto, mesmo quando esses são "coincidentes", como no caso do sujeito com seu corpo. 0 conceito de mimesis em Adorno designa, especialmente no âmbito da Dialética do esclarecimento (H orkheimer; Adorno, 2003; 1985), um comportamento arcaico, expressão da luta pela sobrevivência diante da superioridade opressora da natureza. N essa interpretação, a mimesis não se constitui simplesmente como o outro da razão, mas como uma primeira forma da qual se servem os indivíduos com o objetivo de dominar a natureza, "ambígua protoforma de uma práxis pré-racional" (Zamora, 2008, p. 226, grifo do autor). Essa ambiguidade provém das dimensões que a caracterizam: acomodação alienadora ao espaço morto, ao amorfo; suave adaptação ao singular dos objetos. É sobre essa segunda característica, latente na Dialética do esclarecimento, mas que ganhará inequívoca expressão em obras posteriores de Adorno (notadamente na D ialética negativa e na Teoria estética), que gostaríamos de nos deter na sequência da exposição.

A repressão da dimensão somática do conhecimento que acompanha a formação do pensamento conceitual identificador resulta no (e do) solapamento do impulso mimético que, apesar de deslocado à força por aquele para o âmbito do culto mágico ou da arte, ainda permanece em potência, uma vez que, como destaca H orkheimer (2000, p. 117), "o corpo inteiro é um órgão de expressão mimética." N esse sentido é que permanece, para Adorno, a possibilidade de resgate da mimesis reprimida pelo conceito por meio da autorreflexão, como rememoração da natureza no sujeito, dando voz e expressão à dimensão somático-corporal do conhecimento. Conforme sintetiza Gagnebin (1997, p. 101), a mimesis

[...] indicaria muito maisuma dimensão essencial do pensar, esta dimensão de aproximação não violenta, lúdica, carinhosa, queo prazer suscitado pelas metáforasnos devolve. Ela aponta 
para [...] uma aproximação do outro que consiga compreendê lo sem prendêlo eoprimi-lo, queconsiga dizêlo sem desfigurá Io. Essa proximidadenaqual o espaço da diferençaedadistância seja respeitado sem angústia, esseconhecimento sem violência nem dominação.

Como se pode observar, não se trata, pois, de uma restauração pura e simples do comportamento mimético arcaico no "médium" do pensamento discursivo (Zamora, 2008, p. 226), mas, sim, de resgatá-lo nele - no sentido de rememoração antes apontado. I sso significa considerar, na relação entre racionalidade e mimesis, o distanciamento - entendido como respeito ao outro, ao diferente de si, ou, como dito antes, "proximidade na distância" - entre sujeito e objeto: "essa reconciliação liberaria o não-idêntico, despertando-o por fim da compulsão intelectualizada [...]. R econciliação seria então a rememoração [E ingedenken] sobre a multiplicidade que não se mostraria mais como hostil [...]" (Adorno, 2003, p. 2836; 2009, p. 14, tradução ligeiramente modificada).

$M$ as não é apenas no âmbito da racionalidade conceitual, como autorreflexão sobre o próprio pensamento identificador, que Adorno advoga a dignidade da dimensão mimética. Também na experiência estética, ou seja, na fruição artística - a qual, aliás, guarda íntima relação com a reflexão filosófica, embora com ela não se confunda -, a mimesis joga papel decisivo.

Segundo Adorno, a construção estética é semelhante, em seu princípio, ao processo de síntese queleva ao conhecimento conceitual (pensamento discursivo). Entretanto, a conceitualidade da arte possui um caráter diferente daquele no qual os conceitos atuam como unidade sintética dos traços dos objetos empíricos (Zamora, 2008, p. 230). Como lembra Freitas (2003), para Adorno, a obra de arte, assim como a fruição de sua experiência, não é irracional, ainda que não seja racionalizável de acordo com critérios da lógica científica. Para o filósofo frankfurtiano, a racionalidade estética possui um status sui generis, pois não contém aquele caráter unívoco do conhecimento matemático, mas não é disparatada, absurda. Sua coerência e sua ordenação não devem ser buscadas a partir de um ponto externo à própria obra, pois ela surge a partir da densidade da experiência com o objeto artístico. D ito de outra forma, o conhecimento esté tico não tem como objetivo algo externo à relação entre sujeito e objeto, ou seja, entre 0 fruidor e sua obra (Freitas, 2003). Em grande medida, isso é alcançado pela arte, assevera Zamora (2008, p. 230), libertando a dimensão mimética dos conceitos em seu estrato não conceitual:

$\mathrm{N}$ a esfera estética, o impulso mimético afecta antesa mediação, o conceito, o não-presente. 0 elemento conceptual, enquanto entremeado, éinalienável na linguagem etambém em toda a arte, etransforma-se assim em algo dequalitativamente outro 
em relação aos conceitos enquanto elementos distintivos de objectosempíricos. [...] A arteopõe-setanto ao conceito comoà dominação mas, paratal oposição, precisa, como afilosofia, dos conceitos. (Adorno, 2003, p. 3962; 1988, p. 115).

A conceitualidade característica da arte participa da racionalidade. $\mathrm{N}$ ão se trata, portanto, de uma entrega à natureza e sua circularidade mitológica. Sua força crítica contra a cisão fundadora da racionalidade, aquela que opõe ser humano e natureza, corpo e espírito, como acabamos de ver na citação acima, deriva dessa mesma separação. A arte, para Adorno, não se coloca fora da "dialética do esclarecimento" e tampouco além ou aquém da separação entre sujeito e objeto (Zamora, 2008, p. 231). M imesis e racionalidade estão mutuamente imbricadas também na arte, algo que a técnica testemunha como síntese desse movimento. 0 que é importante frisar, sobretudo em relação aos marcos do presente trabalho, é a possibilidade de mediação entre ambas, que é facultada, segundo Adorno, pela experiência estética, pois nesta encontram refúgio os impulsos espontâneos e idiossincráticos; 0 sofrimento que exige ser expresso; o tratamento aconchegante com os objetos e as coisas, violentamente reprimidos na dominação da natureza pela racionalidade autoconservadora idêntica apenas a si própria. Recorde-se, a propósito, como lemos em Dialética negativa, que o sofrimento, sempre corporal, é um impulso não analgésico ao conhecimento (conceitual ou estético) e que a filosofia de Adorno, mesmo quando apresenta seus traços metafísicos, coloca-se em direção contrária a qualquer bálsamo que faça esquecer a materialidade e, portanto, as fronteiras do corpo. (Adorno, 2003, p. 3146-3149; 2009, p. 172-174). Conforme sintetiza Freitas (2003, p. 36):

U ma vez que o processo de racionalização procurou separar o sujeito do objeto, dando ao primeiro um arcabouço de conceitos, princípios, leisabstratas, quepermitem dominar o outro, a arte procura relembrar ao sujeito sua dimensão de natureza corporal, desejante, através não de sua recaída na magia, na superstição ou irracionalismo, mas sim da estruturação radical da obra. Se, natrajetória do esclarecimento, a razão reprimiu o comportamento mimético, na artea racionalidadeéa mediação necessária para amímesis.

\section{Corpo e mimesis: possíveis implicações para a educação do corpo na escola}

As questões relacionadas à rememoração da natureza no sujeito, como antídoto para contrapor-se ao processo de naturalização da subjetividade, também 
adquirem uma forte dimensão pedagógica, na obra de Adorno, uma vez que, internamente ao horizonte de preocupações do autor em relação a uma educação que possa resistir à reificação da barbárie e à compulsão por ela, hodiernamente, o corpo e suas expressões ocupam lugar privilegiado. Tal dimensão se evidencia, especialmente - embora não exclusivamente -, naqueles escritos de Adorno (2003; 1995a) diretamente vinculados à problemática educacional, vários deles reunidos no livro Erziehung zur M ündigkeit, organizado por Gerd Kadelbach em 1971, dois anos após a morte de Adorno, traduzido e publicado no Brasil em 1995, sob o título de Educação e emancipação. D entre as diferentes questões debatidas nesses escritos, várias das quais estreitamente vinculadas com as práticas corporais na escola, duas merecem, no contexto deste artigo, destaque especial.

A primeira aparece no ensaio "Educação após Auschwitz", no qual Adorno, ao perguntar-se pelas possibilidades de a educação colaborar para a desbarbarização da sociedade e para a tentativa de evitar aquilo que, em termos históricos, culminou nos campos de concentração e extermínio da Alemanha nazista, destacará que, em cada situação na qual a consciência é mutilada (verstümmelt), as consequências refletem-se sobre o corpo e a esfera corporal de uma maneira não livre e propícia à violência e à crueldade (Adorno, 2003, p. 8527-8528; 1995a, p. 126-127). Esta questão sintetiza a relação entre "corpo", "técnica" e "produção da consciência reificada", elementos que se combinam de diversas formas na obra de Adorno, mas encontram seu desiderato na crítica à ambiguidade do progresso, manifestada predominantemente no desenvolvimento científico e tecnológico, no aperfeiçoamento da divisão social do trabalho e na evolução dos meios de comunicação de massa. Ao observarmos, no pensamento adorniano, a relação entre corpo e técnica nos marcos do conceito de domínio da natureza, como desdobramento da questão acima exposta, a técnica pode ser interpretada como uma espécie de segunda natureza, uma "catástrofe" - conceito central na filosofia da história de Adorno -, que engendraria um profundo processo de olvido do passado, da nossa relação de compartilhamento com a natureza, ao mesmo tempo que sua força proviria justamente desse esquecimento. A técnica seria, então, uma forma racional de organizar e potencializar uma relação de severidade e de domínio absoluto sobre o próprio corpo. 0 refinamento trazido pelo aparato tecnológico e a instrumentalidade corporal, que teria seu momento de maior expressão no esporte e no treinamento que ele exige, acabariam convertendo-se em mediadores da perversa equação entre celebração e desprezo, de "amor-ódio" pelo corpo, do qual nos falam H orkheimer e Adorno (2003, p. 1526; 1985, p. 217) na seção final da D ialética do esclarecimento.

A segunda questão, intimamente relacionada a essa primeira passagem, está presente no texto "Tabus acerca do magistério". N ele, ao procurar tornar visíveis 
al gumas das dimensões da aversão/repulsa à profissão de professor - com exceção do professor universitário e seu "inabalável" prestígio - , Adorno constata que sua origem teria, por um lado, bases racionais, como a apatia em relação ao que se encontra regulamentado em torno do professor e da escola, bem como motivações econômicas, relacionadas à imagem do magistério como profissão de fome (H ungerberuf) na Alemanha (Adorno, 2003, p. 8487; 1995a, p. 98).

Por outro lado, haveria um conjunto maior de questões referindo-se às motivações subjetivas, em especial as inconscientes - sedimentações coletivas de representações que perderam suas bases reais, mas que se conservam com muita tenacidade, como preconceitos, que, por sua vez, retroagem sobre a realidade, convertendo-se, então, em forças reais - e representariam tabus em relação à prática de ensinar. Expressão e, simultaneamente, motivação desses tabus que pairam sobre o professor no imaginário social alemão seria, segundo 0 argumento central ali exposto, a função disciplinar por aquele desempenhada. Por trás da imagem negativa do professor encontra-se a do homem que castiga, de alguém que é fisicamente mais forte e agride 0 mais fraco:

o processo civilizatório de que os professores são agentes orienta-se para um nivelamento. Ele pretende eliminar nos alunos aquela natureza disformequeretorna como natureza oprimida nas idiossincrasias, nosmaneirismos dalinguagem, nossintomasde estarrecimento, nos constrangimentosenasinabilidades dos mestres. (Adorno, 2003, p. 8504; 1995a, p. 110; grifo nosso).

Embora essas passagens não sejam as únicas no contexto dos escritos pedagógicos de Adorno a referir-se diretamente ao tema da corporalidadet, nelas é bastante evidente, no que se refere às práticas de educação do corpo, a presença da barbárie contemporânea, engendrada, aliás, no próprio seio da civilização e da racionalidade que lhe é correspondente. Por outro lado, se as condições de existência do domínio sobre o corpo no mundo contemporâneo permanecem contraditórias, Adorno advoga uma educação na qual o processo de nivelamento e de supressão de todo e qualquer vestígio de natureza possa dar lugar à reflexão sobre nosso pertencimento a esta - algo, aliás, determinante, também, nas suas ideias sobre os lugares da arte e da filosofia, reforçando no sujeito, num movimento de inflexão em direção a seu íntimo núcleo, a capacidade de autorreflexão crítica.

Se, ao interrogar-se sobre as possibilidades da educação na formação de uma consciência não danificada, que estabeleça, concomitantemente, uma outra relação com o corpo - já que, como vimos anteriormente, toda a vez que a

4. Sobre os comentários de Adorno a respeito da educação do corpo nos escritos mais diretamente relacionados à problemática educacional, consultar Bassani e Vaz (2003, p. 13-37). 
consciência é reificada, as consequências se refletem na compulsão à violência e no amor-ódio por este - , a resposta de Adorno aponta em direção à autonomia, à autodeterminação e à não participação (das N icht-mitmachen) das pessoas, coloca-se a hipótese da formulação da mesma questão, mas de outra maneira. Tratar-se-ia de perguntar pela possibilidade de, também na educação do corpo, romper com a racionalidade tornada mítica, com a barbárie; ou de indagar se a preocupação de Adorno não poderia ser, nos marcos de seu próprio pensamento, recolocada em outro sentido: em que medida uma relação não patogênica com o corpo pode indicar uma consciência não reificada, uma subjetividade não danificada, na qual a dimensão mimética ganhe importância, estabelecendo uma relação não autoritária entre sujeito e objeto. $N$ ão seria esta uma simples inversão da questão, o elogio de um sensualismo irracionalista a partir da defesa da reconversão romântica do Körper (corpo físico) em Leib (corpo vivo), a qual os próprios frankfurtianos advertiram ser não apenas equivocada, mas também potencialmente regressiva (H orkheimer; Adorno, 2003, p. 1528; 1985, p. 218). Tal como a fruição estética, que se caracteriza como mimesis que reconhece 0 não idêntico e, dessa forma, tem consciência de seus limites de aproximação do objeto, o corpo e suas expressões podem, seguindo as pistas do pensamento de Adorno, constituir-se como experiências que aproximem os indivíduos do que é negado, sem negá-lo, mas sem reproduzi-lo de maneira imediata (D uarte, 1993; Ramos, 2006; Vaz, 2007). Este é um movimento que poderia estar presente na escola, de forma que também no âmbito das práticas corporais poderíamos falar, com Adorno, em "rememoração da nature za no sujeito" (Horkheimer; Adorno, 2003, p. 1167; 1985, p. 50).

Localizar-se-ia nesse registro a ambiguidade do esporte: exercício masoquista de dominação de si no interior de uma pedagogia para a violência autoinfligida, mas também momento de reconhecimento da falibilidade do corpo, de lembrança do que nos é indomável. Em conhecida passagem de “Educação após Auschwitz", assim se coloca Adorno (2003, p. 8528; 1995a, p. 127):

por um lado, ele[0 esporte] podeter efeito contrário à barbárie eao sadismo, por intermédio do fairplay, do cavalheirismo edo respeito pelo maisfraco. Por outro, em al gumas desuas modalidadese procedimentos, elepodepromover a agressão, a brutalidadee o sadismo, principalmenteno caso dos espectadores, quepessoalmentenão estão submetidos ao esforço eà disciplina do esporte; são aqueles que costumam gritar noscamposesportivos.

0 caráter aristocrático do esporte seria, nesses termos, revelador de sua ambiguidade. Como distintivo de classe a ser assumido como parte do etos da 
era burguesa, ele é prática da educação para a virilidade (Gay, 1993) e para o comando. Por outro lado, é também, simultaneamente, recordação de um momento em que 0 sujeito ainda tinha um lugar destacado nas práticas sociais, 0 da ascensão da burguesia e suas promessas. Longe de querer salvar a ordem burguesa, Adorno nela reconhece, melancolicamente, como já fizera Benjamin (1985), e de maneira irônica, o momento de promessa que não foi cumprida.

Ao mesmo tempo, reencontramos o tema da mimesis como expressão nos marcos da possibilidade de fruição estética do jogo, no esporte e em outras práticas corporais, naquela dimensão que possa concorrer, ainda que não necessariamente anular, os momentos agônicos e de predominância da técnica. 0 próprio Adorno (2003, p. 4502-4503; 2004, p. 420-421) sugere essa aproximação, ao considerar as assertivas de $\mathrm{H}_{\text {uizinga }}{ }^{\mathrm{e}}$ em sua valorização do jogo como substrato da cultura (H uizinga, 1993). Embora em discordância com o filósofo holandês, Adorno encontrará no jogo um momento de recordação da natureza, da espontaneidade - mas não de qualquer irracionalidade - proposta no desinteresse das práticas que não podem ser reduzidas ao mero caráter utilitário. M imesis não como superação do domínio da natureza, mas como possibilidade de aproximação não regressiva com o próprio corpo, em duas dimensões.

A primeira, na recordação da debilidade e da finitude do corpo, como movimento de renúncia ao culto à dor e ao sofrimento, muitas vezes predicado pela pedagogia esportiva. 0 enfrentamento da dor, do sofrimento, do sacrifício e da privação é frequentemente encarado como algo corriqueiro e "normal" por parte de atletas - tanto aqueles experientes quanto os iniciantes (Gonçalves; Vaz, 2006; Rubio; G odoy M oreira, 2007) -, bailarinas (Gonçalves; Vaz, 2006), lutadores (Vaz; Gonçalves; Turelli, 2006), frequentadores de academias de ginástica e musculação (H ansen; Vaz, 2004; Torri; Bassani; Vaz, 2007) e alunos(as) do esporte escolar e nas aulas de educação física (Bassani; Torri; Vaz, 2003; Torri; Albino; Vaz, 2007; Vaz; Bassani; Silva, 2002). Esses elementos, constituintes da lógica de treinamento esportivo, mas presentes com força cada vez maior em outros tempos e espaços das práticas corporais, parecem ser menos um efeito colateral do que verdadeiros coadjuvantes dessa batalha - 0 termo, aqui, não menos importante - constante pelo "aperfeiçoamento" corporal (H ansen; Vaz, 2004). De expressão irrenunciável da experiência corporal, a dor parece converter-se, de forma naturalizada, em componente identificador - mas também legitimador - do alcance das aspirações pelo máximo rendimento do corpo, seja associado à performance esportiva (inclusive no âmbito

5. Adorno vale-se também da comparação entre jogo e esporte, tal como em Huizinga (embora sem citá-lo), para falar da degradação da música no texto "O fetichismo da música e a regressão da audição" (Adorno, 2003, p. 11257; 1991b, p. 102-103). 
escolar) ou ao embelezamento e à modelação corporal, já que se trata de uma "dor boa", sinal de "resultados" e "progressos" do/sobre o corpo.

A segunda dimensão seria como momento espontâneo a ganhar forma pela cultura, ou seja, pela técnica e pela tradição dos esportes, mesmo que em movimento de resistência a seus ardis reificadores. Embora a crítica de Adorno à técnica seja radical (Bassani; Vaz, 2008), o frankfurtiano não se deixa levar pela simples condenação peremptória, mas guia-se pela força contraditória que a técnica, como expressão iluminista, em conjugação com o sentido espontâneo e não conceitual do conhecimento, dado pela mimesis, permite conhecer sobre a relação com a natureza, tanto externa quanto interna ao ser humano.

Para além do potencial heurístico de sua vasta obra, Adorno oferece-nos, sem receitas, mas no impulso crítico de suas preocupações educacionais, uma forte inspiração para a reflexão epistemológica, mas também pedagógica, sobre educação do corpo e suas expressões.

\section{Referências biblio gráficas}

AD O RN O, T. W. Gesammelte Schriften. Frankfurt am M ain: Suhrkamp, 1986; Berlin: D irectmedia, 2003. (D igitaleBibliothek Band 97).

AD 0 RN 0 , T. W. Teoria estética. Trad. Artur M orão. Lisboa: Edições 70, 1988.

AD O RN O, T. W. Actualidad dela Filosofia. Trad. José Luis Arantegui Tamayo. Barcelona: Paidós, 1991a.

AD O RN O , T. W. O spensadores(Adorno eH orkheimer). São Paulo: Abril Cultural, 1991b.

AD O RN O ,T. W. M inima M oralia: reflexõesa partir davidadanificada. Trad. deLuizEduardo Bicca. 2. ed. São Paulo: Ática, 1993.

AD O RN O , T. W. Educação eemanci pação. Trad. Wolfgang Leo M aar. Rio de Janeiro: Paz e Terra, 1995 .

AD O RN O, T. W. Palavrasesinais modeloscríticos2. Trad. M ariaH elena Ruschel. Petrópolis: Vozes, 1995b.

AD 0 RN 0, T. W. Teoríaestética. Trad. JorgeN avarro Pérez. In: AD O RN O , T. W. 0 bra completa. M adrid: Akal, 2004. v. 7.

AD O RN O ,T. W. D ialética negativa. Trad. M arco Antonio C asanova. R io de Janeiro: Jorge Zahar, 2009.

AGAM BEN , G. 0 príncipe e o sapo: o problema do método em Adorno e Benjamin. In: AGAM BEN , G. Infância e história: destruição da experiência e origem da história. Belo H orizonte: Editorada U FM G , 2005. p. 129-149.

ALVESJÚ N IO R, D . G . Reconciliação erememoração da naturezano sujeito: Adorno eaquestão da possibilidadedafilosofia. Educaçãoe eFilosofia, v. 15, n. 30, p.117-130, jul./dez. 2001. 
BASSAN I, J. J.;TO RRI, D .; VAZ, A. F. Sobrea presença do esportena escola: paradoxose ambigüidades. M ovimento, Porto Alegre, v. 9, n. 2, p. 89-112, maio/ago. 2003.

BASSAN I, J . J.; VAZ, A. F. Comentários sobrea educação do corpo nos "textos pedagógicos" de Theodor W. Adorno. Perspectiva, Florianópolis, v. 21, n. 1, p. 13-37, jan./jun. 2003.

BASSAN I, J. J.; VAZ, A. F. Técnica, corpo e coisificação: notas de trabal ho sobre o tema da técnica em Theodor W. Adorno. Educação \& Soci edade, v. 29, p. 99-118, 2008.

BEN J AM IN , W. O brasescolhidasI : magiaetécnica, arteepolítica. 4. ed. São Paulo: Brasiliense, 1985.

BU CK-M O RSS, S. O rigen dela dialéctica negativa: Theodor W. Adorno, Walter Benjamin y el Instituto deFrankfurt. Trad. N ora R. M askivker. Cerro del Agua: Siglo XXI Editores, 1981.

CH IARELLO , M . Em defesa de Adorno: a propósito das críticas endereçadas por Giorgio Agamben à dialética adorniana. Kriterion: Revista deFilosofia, Belo H orizonte, v. 48, n. 115, p. 183-201, 2007.

DUARTE, R. M ímesiseracionalidade São Paulo: Loyola, 1993.

FREITAS, V. Adorno ea artecontemporânea. Rio deJaneiro: Zahar, 2003.

GAGN EBIN , J. M . Seteaulassobrelinguagem, memória ehistória. Rio deJ aneiro: I mago, 1997.

GAG N EBIN , J. M . D ivergências e convergências sobre o método dialético entreA dorno e Benjamin. In: PU CCI, Bruno; GO ERG EN , Pedro; FRAN CO, Renato. (O rg.). D ialética negativa, etética eEducação. C ampinas: Alínea, 2007. v. 1, p. 67-88.

GAY, P. Thecultivation of hatred. N ew York: N orton \& Company, 1993.

GO N Ç ALVES, M . C.; VAZ, A. F. D or esofrimento: o domínio desi esuasrepresentaçõesna vida deatletasebailarinos. In: REU N IÃO BRASI LEIRA DE ANT RO PO LO GIA, 25., 2006, Goiânia. G oiânia: ABA, 2006.

H AN SEN , R.; VAZ, A. F. Treino, culto eembelezamento do corpo: um estudo em academias deginástica e musculação. Revista Brasileira deCiência do Esporte, C ampinas, v. 26, n. 1, p. 135-152, set. 2004.

H O RKH EIM ER, M . Eclipseda razão. São Paulo: Centauro, 2000.

H O RKH EIM ER, M .; AD O RN O ,T. W. D ialética do esclarecimento: fragmentosfilosóficos. Trad. Guido Antônio deAlmeida. Rio de Janeiro: Zahar, 1985.

H O RKH EIM ER, M .; AD O RN O ,T. W. D ialektik der Aufklärung: PhilosophischeFragmente. In: AD O RN O , T. W. G esammelteSchriften. Frankfurt am M ain: Suhrkamp, 1986; Berlin: D irectmedia, 2003. (D igitaleBibliothek Band 97). p. 1087-1643.

H UIZI N G A, J. H omo ludens. Trad. João P. M onteiro. 2. ed. São Paulo: Perspectiva, 1993.

JAY, M . AsidéiasdeAdorno. Trad. Adail U . Sobral. São Paulo: Cultrix; Ed. daU SP, 1988.

N O BRE, M . Excurso: Theodor Adorno eWalter Benjamin 1928-1940. In: N O BRE, M .. A dialética negativa deT heodor W. Adorno: a ontologia do estado falso. São Paulo: Fapesp; Iluminuras, 1998. p. 59-102. 
RAM O S, C. O ressentimento do guerreiro: reflexões sobre corpo e educação a partir do pensamento deT heodor Adorno eda Psicanálise. Interações- U niversidade São M arcos, v. 11, p. 9-28, 2006.

RUBIO , K.; GO D OY M O REIRA, F. A representação de dor em atletasolímpicos brasileiros. Revista D or, São Paulo, v. 8, p. 926-935, 2007.

TORRI, D .; ALBIN O , B. S.; VAZ, A. F. Sacrifícios, sonhos, indústria cultural: retratos da educação do corpo no esporte escolar. Educação ePesquisa - U SP, v. 33, p. 499-512, 2007.

TO RRI, G., BASSAN I, J. J.; VAZ, A. F. D or etecnificação no contemporâneo culto do corpo. Pensar a Prática - UFG, v. 10, p. 261-273, 2007.

VAZ, A. F. Treinar o corpo, dominar a natureza: notas para uma análise do esportecom baseno treinamento corporal. CadernosCED ES - Corpo eEducação, Campinas, n. 48, p. 89-108, 1999.

VAZ, A. F. N otas conceituais sobre mímesis e educação do corpo em M ax H orkheimer e Theodor W. Adorno. In: PU CCI, Bruno; GO ERG EN , Pedro; FRAN CO, Renato. (O rg.). D ialética negativa, etética eEducação. C ampinas: Alínea, 2007. p. 189-202.

VAZ, A. F.; BASSAN I, J. J.; SI LVA, A. S. da. Identidades e rituaisna educação do corpo na escola: um estudo em aulas de educação físicano ensino fundamental. M otusC orporis, Rio de Janeiro, v. 9, n. 2, p. 23-39, 2002.

VAZ, A. F.; G O N ÇALVES, M . C.; TU RELLI, F. C. C orposesubjetivações: notas depesquisa sobre o fluxo de identidades no esporte, na luta, no balé. In: REUNIÃO AN UAL DA AN PO C S, 30., Caxambu: AN PO C S, 2006.

ZAM O RA, J. A. Th. W. Adorno: pensar contra a barbárie. São Leopoldo: N ova H armonia, 2008.

Recebido em 09 de fevereiro de2010 eaprovado em 07 dejulho de2010. 
